\title{
DYED NATURAL CORUNDUM AS A RUBY IMITATION
}

\author{
By K. Schmetzer; H. A. Hänni, E. P. Jegge, and F.-J. Schupp
}

\begin{abstract}
The gemological properties of a new ruby imitation, produced by dyeing natural colorless to pale-colored corundum, are described. Microscopic and spectroscopic examination revealed a number of diagnostic features: fluorescence of the dye-containing fissures but not the surrounding corundum, red deposits on the fracture planes, and the absence of a 694-nm (chromium) doublet in the spectrum.
\end{abstract}

Various treatments are known for natural ruby and sapphire. These include irradiation, heat treatment, diffusion treatment, synthetic ruby and sapphire overgrowths, and the filling with glass or organic substances (oil, paraffin, resin, epoxy, etc.) of surface-reaching cavities and fissures. ${ }^{*}$ Such treatments have been described extensively in the literature, for example: Gübelin, 1961; Crowningshield, 1979; Nassau, 1981; Koivula, 1983; Scarratt and Harding, 1984; Kane, 1984; Schmetzer, 1986, 1988; Hänni, 1988; and Kammerling et al., 1990.

Most of the corundum treatments reported to date are performed to improve the visual appearance and/or stability of the natural stones. Occasionally, Verneuil flame-fusion synthetic corundum is subject to "quench crackling" (heating then rapid cooling by immersion in a liquid) and subsequent flux treatment to mask its synthetic origin by producing artificial fingerprint-like inclusions (Koivula, 1983; Kane, 1985; Schmetzer, 1986).

\section{ABOUT THE AUTHORS}

Dr. Schmetzer is a research scientist residing in Petershausen, Germany. Dr. Hänni is director of the Swiss Gemmological Institute (SSEF), Zürich, and associate professor of gemology at Basel University, Switzerland. Mr. Jegge is staff gemologist at SSEF. Mr. Schupp is a gemstone dealer who resides in Frorzheim, Germany.

Gems \& Gemology, Vol. 28, No. 2, pp. 112-115.

(C) 1992 Gemological Institute of America
Recently, the authors encountered a new corundum treatment, whereby fractures are induced in natural colorless to pale-colored sapphire and then dyed to produce a purplish red imitation of ruby. The red staining of fissures induced in quartz by quench crackling has been used for centuries to imitate ruby (see, e.g., Fryer et al., 1981; Nassau, 1984), but to our knowledge this is the first report of such a treatment being used on corundum.

\section{BACKGROUND}

In late 1991 (see International Colored Stone Association [ICA] Alert No. 50, December 1991), four strands of flattened spherical beads (figure 1) were submitted to the SSEF laboratory in Zürich for testing. The beads had reportedly been manufactured in India; the largest were $15 \mathrm{~mm}$ in diameter (approximately $10 \mathrm{ct}$ ).

Some beads exhibited large areas that were colorless to pale yellow (again, see figure 1). We subsequently determined, using the techniques discussed below, that they had been dyed.

\footnotetext{
"According to CIBJO rules for treatments of natural corundum, all such treatments of natural stones, with the exception of a simple heat treatment (performed without any addition of chemicals and/or color-causing trace elements), must be disclosed to the consumer. All of the above-mentioned treatments for corundum are identified on official identification reports issued by GIA's Gem Trade Laboratory. In contrast to CIBJO rules, this also includes disclosure of heat treatment of rubies and sapphires.
} 
It appears that the process was later improved, because six faceted samples subsequently submitted to one of the authors (see, e.g., figure 2) displayed no colorless areas when examined with the unaided eye. According to information from the supplier, these faceted ruby imitations were purchased in India as heat-treated Indian rubies. The sizes of these six stones ranged from about 5 to $8 \mathrm{ct}$, and the diaphaneity ranged from semitransparent to translucent. Because of their purplish red color, the samples closely resembled some Indian rubies. Again, as described below, standard gemological testing readily revealed that they had been dyed.

\section{GEMOLOGICAL AND SPECTROSCOPIC CHARACTERISTICS OF THE DYED CORUNDUM}

On preliminary examination, the beads and faceted stones appeared to lack any remarkable features: Both the refractive index and specific gravity values were normal for corundum. Surprisingly, the fluorescent doublet at $694 \mathrm{~nm}$ did not show up when the hand spectroscope was used. When exposed to long-wave ultraviolet radiation, the stones lacked the red fluorescence typical of rubies from many localities, but the fractures fluoresced an intense yellow-orange. Also unlike most rubies, the stones were inert to short-

Figure 1. Virtually all of these "flattened" red beads, which were reportedly manufactured in India, contained large, distinct, colorless areas. The beads shown here are approximately $10 \mathrm{~mm}$ in diameter, Photo by H. A. Hänni.

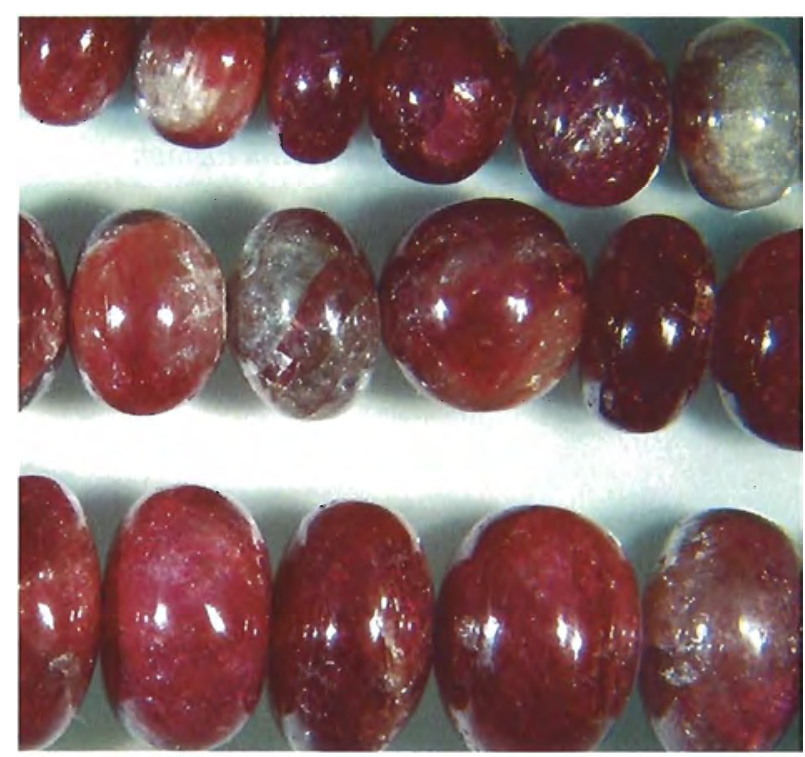

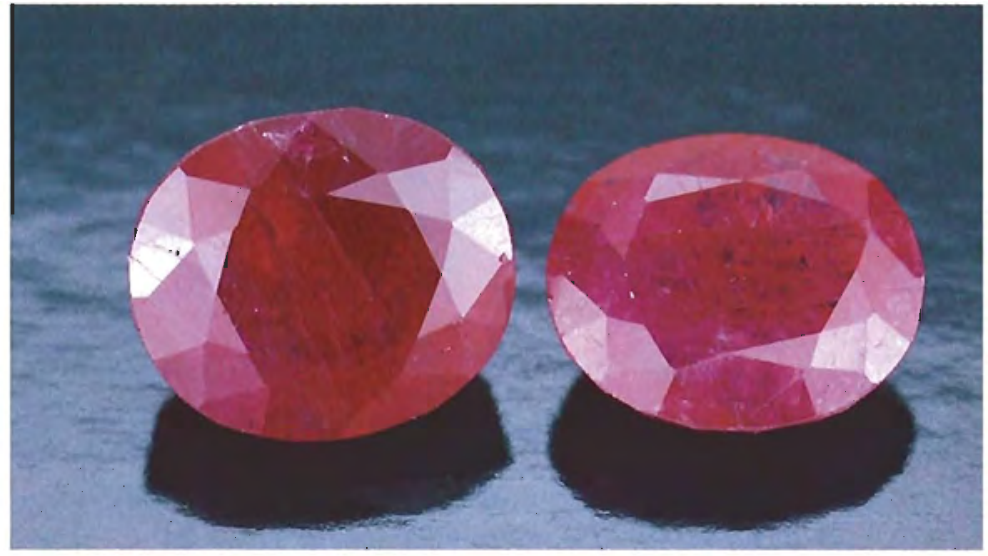

Figure 2. These faceted stones were found to have been treated by a method similar to that used to color the conundum beads shown in figure 1. However, no colorless areas could be seen in these stones with the unaided eye. Photo $\subseteq$ GIA and Tino Hammid.

wave U.V. radiation. We subsequently determined that these features appear to be characteristic for this imitation.

A common test for dye is to rub a cotton swab dipped in acetone across the surface of a suspect sample to see if any color comes off on the swab. We tried this on some of our samples, but observed no dye on the swab. Nor did we detect any evidence that the fractures had been sealed at the surface to prevent detection by the cotton swab test or to keep the dye from being removed.

Examination of both the beads and the faceted stones with the microscope revealed identical and diagnostic properties. In all samples examined, the red color was deposited only in irregular fracture planes. Unstained areas between fractures were seen mainly at the girdle region. They were easily observed when the stones were immersed in liquid, even if it was only water (figure 3). Because the stained fractures were so densely distributed, they were more difficult to see in the thicker areas (figure 4).

The stones also contained various natural inclusions. Dense sets of parallel twin lamellae were observed in one or two directions. Particles of what appeared to be boehmite were confined to the intersection lines of the latter lamellae. Small, doubly refractive mineral inclusions, probably zircon or apatite (or both), were common (figure 5). These inclusion characteristics strongly resemble those of conundum from the Umba Valley of Tanzania (Schmetzer, 1986; Hänni, 1987). 


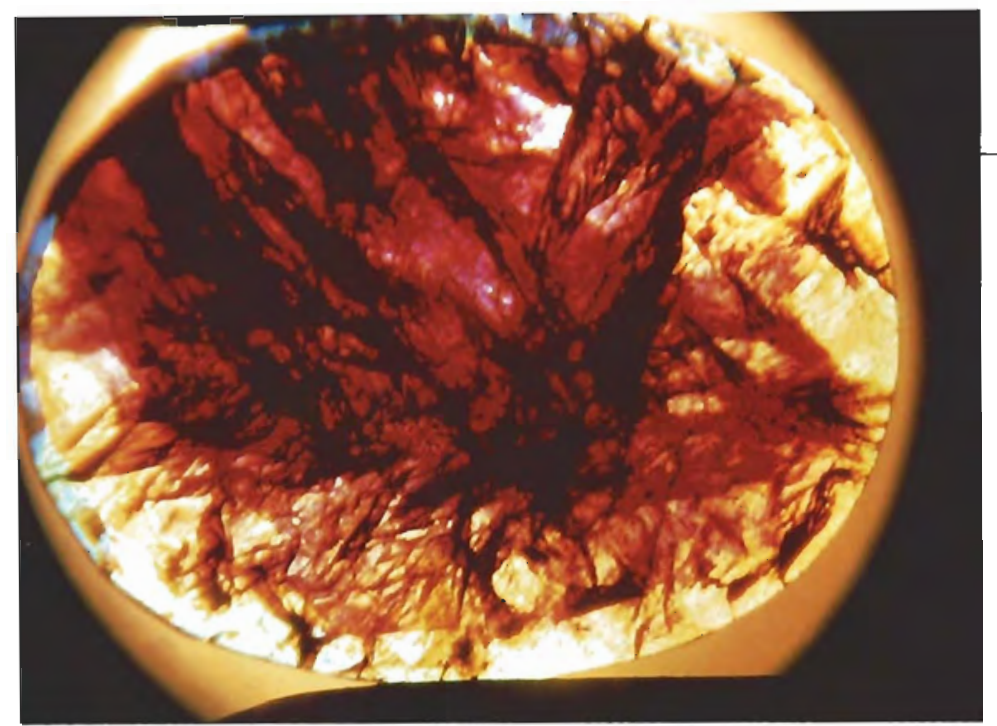

Figure 3. With low magnification and immersion in water, colorless areas were readily apparent along the girdle of this faceted ruby imitation. Photomicrograph by H. A. Hänni; magnified 20x.

The absorption spectrum of the new ruby imitation, recorded on a Pye-Unicam SP8-100 U.V.-visible spectrophotometer, revealed additional diagnostic features. Specifically, the stones we studied lacked the chromium lines in the red area of the spectrum that are characteristic of ruby and responsible for its typical red fluorescence (figure 6). Yet these ruby imitations did show strong $\mathrm{Fe}^{3+}$ absorption bands in the blue-green $(450 \mathrm{~nm})$ and ultraviolet $(374,388 \mathrm{~nm})$ regions of the spectrum, which are consistent with spectral features observed in yellow sapphires and other $\mathrm{Fe}^{3+}$-containing corundum from the Umba Valley. Even with a hand spectroscope, the $450-\mathrm{nm}$ line due to $\mathrm{Fe}^{3+}$ was evident; again there was no

Figure 4. Virtually no colorless to pale-colored areas are visible in the thicker portions of the dyed stones examined, although the uneven color distribution along irregular fracture planes is readily apparent. Photomicrograph, taken with the stones immersed in water, by H. A. Hänni; magnified $40 x$.

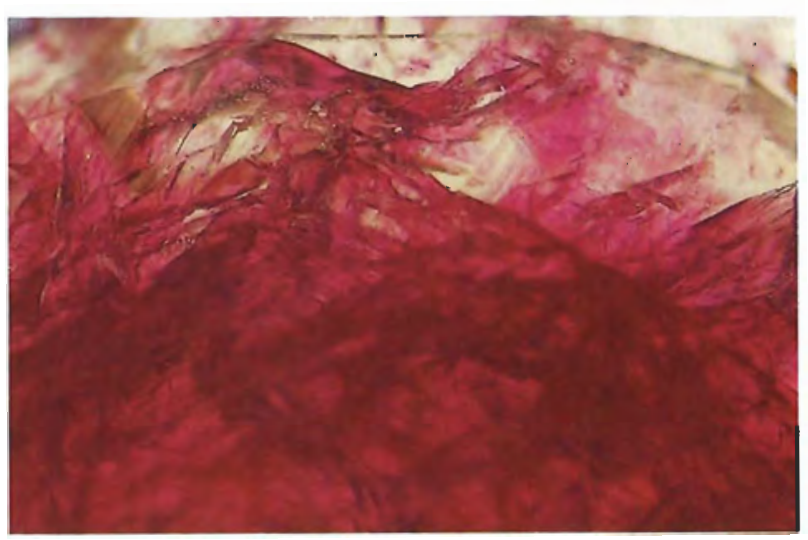

chromium absorption. This evidence also strongly suggests that the stones probably came from the Umba region.

Energy dispersive X-ray fluorescence analysis, performed on a Phillips 9500 , confirmed the presence of iron in the samples and revealed no other color-causing trace elements.

The dominant absorption band in the spectrum of these ruby imitations has a maximum at about 560 $\mathrm{nm}$, with a shoulder at about $530 \mathrm{~nm}$. These two absorption maxima are close to the position of the major chromium absorption band (at about $550 \mathrm{~nm}$ ) typically found in the visible spectrum of ruby (again, see figure 6). The similarities in the main peak position of ruby and the artificial dye are responsible for the convincing color of the imitation.

\section{DISCUSSION}

The results of microscopic examination indicate that colorless to pale-colored natural conundum was treated to produce a purplish red ruby imitation. Comparison of the microscopic properties of the dyed ruby imitation with those of natural rubies and sapphires from various sources revealed that the greatest overlap of characteristics occurred with corundum from the Umba Valley, Tanzania (see, e.g., Schmetzer, 1986; Hänni, 1987).

Large quantities of colorless and pale-colored sapphires have been mined at Umba. Such hues are not in demand for jewelry purposes, and research has shown that these stones cannot be transformed into blue or brilliant yellow by simple heat treatment. It appears that a dyeing process has been chosen to improve the marketability of pink, pale green, brown,

Figure 5. Rounded crystals of what appear to be zircon, some showing stress fractures, were seen in the dyed corundum examined. Photomicrograph by H. A. Hänni; magnified $60 x$.

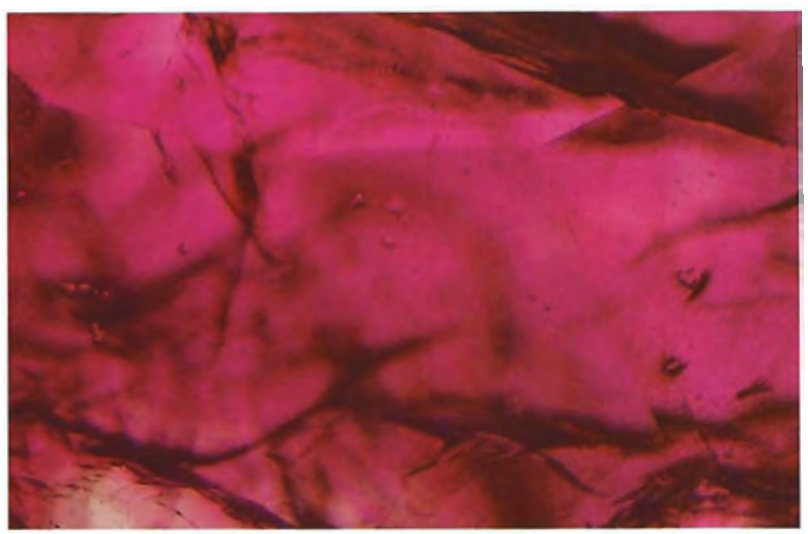




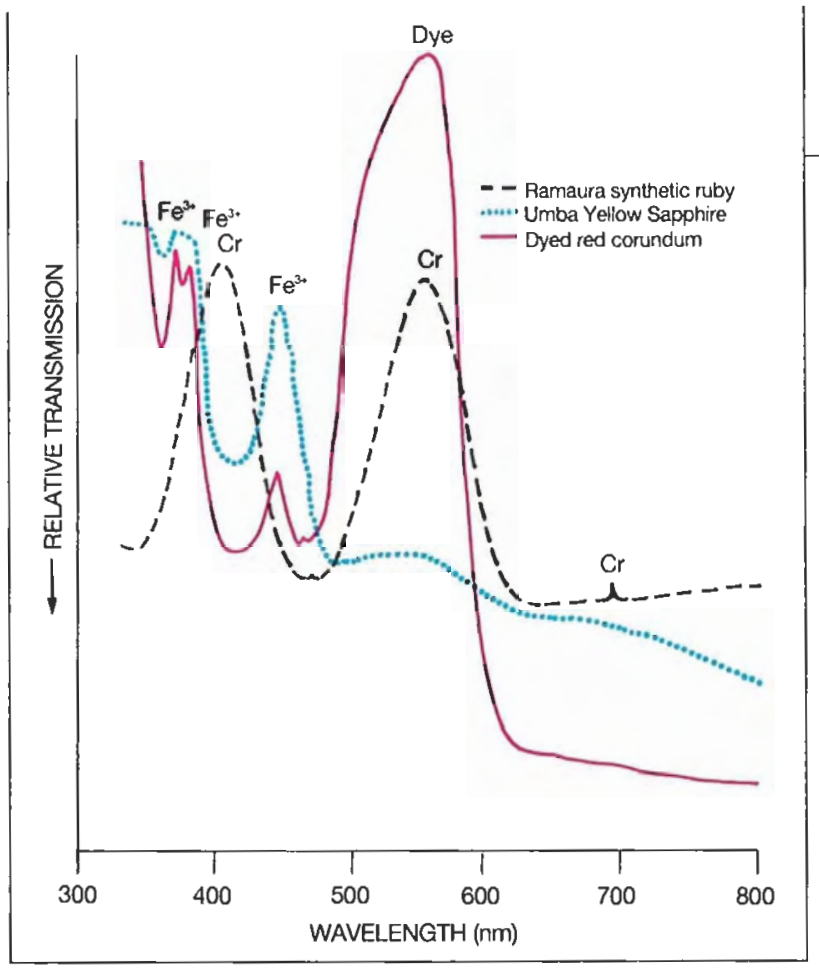

Figure 6. Dominant iron $\left(\mathrm{Fe}^{3+}\right)$ bands were evident in the absorpton spectra of both the dyed ruby imitation and the Umba yellow sapphire. The spectrum of the ruby imitation also shows a maximum at $560 \mathrm{~nm}$, undoubtedly due to the presence of dye, that mimics the absorption typical of ruby (represented here by a Ramaura synthetic ruby).

or any other color type that would be too pale for commercial usage.

At present, we do not know the exact process used. However, it is probably a method similar to the quench crackling of quartz. The corundum, like quartz, would first be heated, quenched, and then immersed in a red dye that would be gradually absorbed into the fractures caused by the stress of rapid cooling. In the stones examined here, the absorption maximum of the dye corresponds to that of ruby, which explains the convincing color of the imitation. However, the strong $\mathrm{Fe}^{3+}$ absorption bands are characteristic of the $\mathrm{Fe}^{3+}$-containing corundum presumably used as the starting material.

It is likely that this process will also be used to produce blue sapphire imitations from the same rough material. Gemologists and jewelers alike should beware of the possible entry of such material into the market.

\section{CONCLUSION}

Natural colorless and pale-colored corundum, probably from Tanzania, was subjected to an artificial staining process, most likely by heating and subsequent quenching in red dye. Although this ruby imitation showed natural inclusions and produced no evidence of dye when wiped with an acetone-soaked swab, the fact that it had been treated was readily recognized by the irregular color distribution. In addition, when sample stones were examined with immersion at low magnification, films of red stain were seen to occur only in the fracture planes; larger, unstained areas between the fractures appeared colorless or pale colored. Since the original corundum does not contain chromium, the stones also lack the characteristic red fluorescence of ruby and the related $\mathrm{Cr}$ lines usually visible with a spectroscope. A yellow fluorescence confined to stained fracture planes may provide the first clue to correctly identifying this ruby imitation.

\section{REFERENCES}

Crowningshield R. (1979) Developments and highlights at GIA's lab in New York: Some sapphire problems. Gems \&4) Gemology, Vol. 16, No. 7, pp. 194-196.

Fryer C.W., Crowningshield R., Hurwit K.N., Kane R.E. (1981) Dyed "crackled" quartz. Gems epl Gemology, Vol. 17, No. 4, pp. 229-230.

Gübelin E.J. (1961) More light on beryls and rubies with synthetic overgrowth. Gems e) Gemology, Vol. 10, No. 4, pp. 105-113.

Hänni H.A. (1987) On corundums from Umba Valley, Tanzania. Journal of Gemmology, Vol. 20, No. 5, pp. 278-284.

Hänni H.A. (1988) An oil well in your garden? Swiss Watch $\Theta)$ Jewelry Journal, No. 3, pp. 461-464.

Kammerling R., Koivula J.I., Kane R.E. (1990) Gemstone enhancement and its detection in the 1980s. Gems 4 Gemology, Vol. 26, No. 1, pp. 32-49.

Kane R.E. (1984) Natural rubies with glass-filled cavities. Gems \&) Gemology, Vol. 20, No. 4, pp. 187-199.
Kane R.E. (1985) A preliminary report on the new Lechleitner synthetic ruby and synthetic blue sapphire. Gems $e_{\text {Gemology, }}$ Vol. 21, No. 1, pp. 35-39.

Koivula J.I. (1983) Induced fingerprints. Gems « Gemology, Vol. 19, No. 4, pp. 220-227.

Nassau K. (1981) Heat treating ruby and sapphire: Technical aspects. Gems \&) Gemology, Vol. 17, No. 3, pp. 121-13I.

Nassau K. (1984) The early history of gemstone treatments. Gems (4) Gemology, Vol. 20, No. I, pp. 22-33.

Scarratt K., Harding R.R. (1984) Glass infilling of cavities in natural ruby. Journal of Gemmology, Vol. 19, No. 4, pp. 293-297.

Schmetzer K. (1986) Natürliche und synthetische RubineEigenschaften und Bestimmung. Schweizerbart, Stuttgart, Germany.

Schmetzer K. (1988) Lechleitner synthetic rubies with natural seed and synthetic overgrowth. Joumal of Gemmology, Vol. 21, No. 2, pp. 95-101. 